INTERNATIONAL JOURNAL OF

\title{
Analysis of Human-Elephant Conflict in Sri-Lanka by The Win-Win-Win Papakonstantinidis Model
}

\author{
"Leonidas A. Papakonstantinidis, "*T.G. Supun Lahiru Prakash \\ * Department of Business Administration, University of Peloponnesus, Greece \\ * * Department of Forestry and Environmental Science, \\ University of Sri Jayewardenepura, Sri Lanka \\ Corresponding author: \\ papakon@gmail.com
}

\section{ABSTRACT}

Asian Elephants have been revered for centuries and playing an important role in the continent's culture and religion where they habitat. Sri Lanka plays an important role in Asian elephant conservation in accommodating more than $10 \%$ of the global Asian elephant population in less than $2 \%$ of global Asian elephant range. Human - Elephant conflict (HEC) is a significant component in Socio - economic development in Sri Lanka and conservation of free range elephants. In this study we attempted to Analysis Human-elephant conflict in Sri-Lanka using the win-win-win Papakonstantinidis model.

Keywords:

Asian Elephants, Human - Elephant Conflict, Wildlife Management, Wildlife Conservation, Economic development 


\section{INTRODUCTION}

Asian Elephants have been revered for centuries and playing an important role in the continent's culture and religion where they habitat. They are also play an important role in maintaining the region's forests (WWF, 2017). Asian Elephants (Elephas maximus) are listed as 'Endangered species' and recorded in isolated populations in 14 states. Their mean population was estimated at 43,445 individuals. Asian elephant population size has reduced to be at least 50\% over the last three generations due to reduction of quantity and quality of habitat and limited to a very approximate total home range of $486,800 \mathrm{~km}^{2}$. (IUCN, 2008; Fernando and Pastorini, 2011).

Sri Lanka plays an important role in Asian elephant conservation in accommodating more than $10 \%$ of the global Asian elephant population in less than $2 \%$ of global Asian elephant range (Leimgruber et al., 2003; Fernando and Pastorini, 2011). Sri Lanka also has one of the highest human densities among range countries (Fernando and Pastorini, 2011). The wild elephant population in Sri Lanka was estimated at 5879 in 2011 (DWC, 2013).The major threat to elephants in Sri Lanka is habitat loss and fragmentation through conversion to human settlements and permanent cultivation and the ensuing humanelephant conflict (HEC). Habitat loss continues to occur at an ever increasing pace especially with the drive for post war 'development', fueling HEC. Elephants are currently found over almost the entire dry zone in an area approximately 60\% of the island and HEC occurs over most of elephant range (Fernando et al., 2011).
The agency mainly responsible for mitigating $\mathrm{HEC}$ is the Department of Wildlife Conservation (DWC).The main methods used in mitigating HEC are crop guarding, chasing elephants from the vicinity of crop fields and villages, elephant drives, capture translocation and electric fencing (Fernando, 2006; Fernando et al., 2008). However, these mitigation measures did not show adequate success and the HEC is increasing day by day up to serious socio-economic problem (Prakash, 2014). In this study we attempted to Analysis Human-elephant conflict in Sri-Lanka using the win-win-win Papakonstantinidis model. We have taken into consideration that human's deaths interact with the elephants' deaths; a "game" (interaction) is raised, with the "conflict payoffs" for both parts. Our research, in this point is focused on building the "possibility" to "find" the equilibrium point, taking into account that human rationality is "balanced" with the elephants' natural power and their un-expected behavior.

\section{MFTHODS}

Human and elephant deaths, human injuries, and property damages in the six wildlife administrative regions over the ten year period of 2006 - 2015 were extracted from the Annual Performance reports of the DWC (DWC, 2015). Our main approach ${ }^{\mathbf{1}}$, intends to prove that the "Environmental Protection" is combined with "social welfare" and social behavior, in terms of sensitization in a well-defined convex area can coexist with the capitalist economic model based on a "tri-polar" (instead of bipolar) perception of any interaction between people-elephants including the

1. all colleagues took part in the research that was conducted, gathered and worked the material that gathered ; all these required hard scientific work

2. Papakonstantinidis LA (2010)"Socio-sustainable Development, ION Ed 2010 
Community (The Intermediate Community- the "C" factor), in 3D space, with the community as "rainbow" synthesis/analysis It is the "rainbow concept" ${ }^{3}$. Finally, at the same time we try to find if and when the proposed methodological tool, the "win-winwin Papakonstantinidis model" is applied in the big data ${ }^{4}$.

\section{Historical View}

This analysis will go further as an alternative, game/bargaining analysis' expression. As technology go on with faster "jumps" from the one point to the other, at the same time, human, economic, social, and psycho relations are changed faster and faster. Especially, the capital socio-economic system dominated on the others during the industrialization, 18th century, (and recently on the communism, 20th century). In the field of socio-economic relations, was noted a double trend: Leaving the Classical Economic School with the "morality" in focus"(Adam Smith, David Ricardo, Carl Marx, John Stuart Mill it passed in the NewClassical, [focusing on short-term equilibrium"] (Alfred Marshal, Leon Walras, John Hicks, and Alle) Neoclassical economics is an approach to economics focusing on the determination of goods, outputs, and income distributions in markets through supply and demand Marginal Economics can be the result of this. As the new-classical economic school was "ready" to be overcome, a new theory has been arisen as a "theory of everything" the game theory and its bargai- ning problem. On this bargaining problem our approach - tabled on Visby University Gotland SW at the 2002-14-08 session -as an extension of "Nash Equilibrium" (NE) was treated, taking into account the community as the third part of a bargain/ any bargain between two. As it will be presented below, the global "trend" today is rather the convergence toward new ethical values, i.e. participatory democracy, social cooperative enterprises, social economy, the third pole of the economy, green growth, local development, natural environment etc.

\section{ANALYSIS}

On this point, a bargaining approach is introduced, in order to study the "humanelephants conflict" as a "game", or even as a "bargain" with its Equilibrium Solution (Nash, 1950). The innovative concept here is that the human have the most weight of responsibility, as elephants follow only their instinct and nothing more. From this point of view, a brief note to the win-win-win Papakonstantinidis bargaining approach is needed.

According to Papakonstantinidis (2003, 2004a, 2004b, 2007), the conditions describing the bargaining situations of the win-win-win papakonstantinidis model are as follows:

1. In a bargaining situation, there are two distinguishable entities with opposite expectations and opposite interests.

3. Papakonstantinidis L.A (2016) the "Rainbow Concept": "Social Welfare" Part of the Book, Dardanos Ed.

4. Big data is data sets that are so voluminous and complex that traditional data processing application software are inadequate to deal with them. Big data challenges include capturing data, data storage, data analysis, search, sharing, transfer, visualization, querying, updating and information privacy. There are three dimensions to big data known as Volume, Variety and Velocity. Lately, the term "big data" tends to refer to the use of predictive analytics, user behavior analytics, or certain other advanced data analytics methods that extract value from data, and seldom to a particular size of data set. "There is little doubt that the quantities of data now available are indeed large, but that's not the most relevant characteristic of this new data ecosystem."Analysis of data sets can find new correlations to "spot business trends, prevent diseases, combat crime and so on." Scientists, business executives, practitioners of medicine, advertising and governments alike regularly meet difficulties with large data-sets in areas including Internet search, fintech, urban informatics, and business informatics. Scientists encounter limitations in e-Science work, including meteorology, genomics, connectomics, complex physics simulations, biology and environmental research (wiki) 
2. These distinguishable entities, with the precisely opposite expectations, should be motivated (for individual benefit), so that they are activated and they transform the opposite expectations in opposite interests and from there in opposite "strategies of victory, or sovereignty".

3. Since we accept the existence of the "distinguishable entity" and the motive of individual profit, we must accept the following condition: the mistrust of each pole of the bargaining situation, regarding the intentions of other. Two distinguishable entities have different expectations; otherwise, the expectation of each one would be identified with the expectation of other.

4. The natural tendency of individuals to improve continuously their position, results as basic consequence of the above assumptions, but simultaneously recommends the reason for all above. This natural tendency is permanent. It does not have upper barrier, while on the contrary it has a lower one.

5. Tendency to conflict, which refers to the tendency to competition between the two parts of the bargain with different expectations and controversial interests, results from the combination of: a) the case of the distinguishable entity, b) mistrust of each distinguishable entity and c) tendency to improvement.

6. Tendency to sovereignty, which refers to the reason for which it is repeated, is in order to stress the importance of "need" for sovereignty, which finally "shapes" the expectations.
7. The strategic choice, the decision and the strategic plan: If all the above aim to achieve the strategic goal of sovereignty, then the strategic plan is the means for accomplishing such a goal.

8. The respect of each one of the two poles, in the rationalism of the other, without moral or other extensions. This is essential and necessary condition for the establishment of the bargaining (in opposite case, there is no negotiation, but simply a "sovereignty" of the one pole to the other). Each one from the two opposite poles just simply respects the "bargaining power of the other", or the "rationalism of the other", which is about "a better organized strategic plan for the achievement of sovereignty".

9. The two "opposite" poles are involved in a bargaining situation through the STRICT choices (that have resulted from rationalism and strategies for sovereignty that shape their final decisions), they never regret for their choices and for their final decisions.

One of the applications of the win-win-win Papakonstantinidis model (since 2002/14/08) is on innovative concept of including a third part, the community (as a total of Values, traditions, ethos) in their conflict relations, between human-elephants. The procedure followed this concept, is the so-called "sensitization" Transferring a two-pole conflict relation in a three-pole, it is expected to be created a more harmonic and balanced human-elephants relation. This concept defines also the borders between human actions and elephants' instinct reaction. At any case a short description of the bargaining problem and its win-win-win perspective with its math prove is needed. 
The bargaining problem is a "share problem, not a binomial term"

From this point of view, "payoffs" are the incentives, for which 2 bargainers start negotiations The final [agreement or not agreement] are the outcome In this proposed method, we recognize that "When two negotiators pushed by expected payoffs

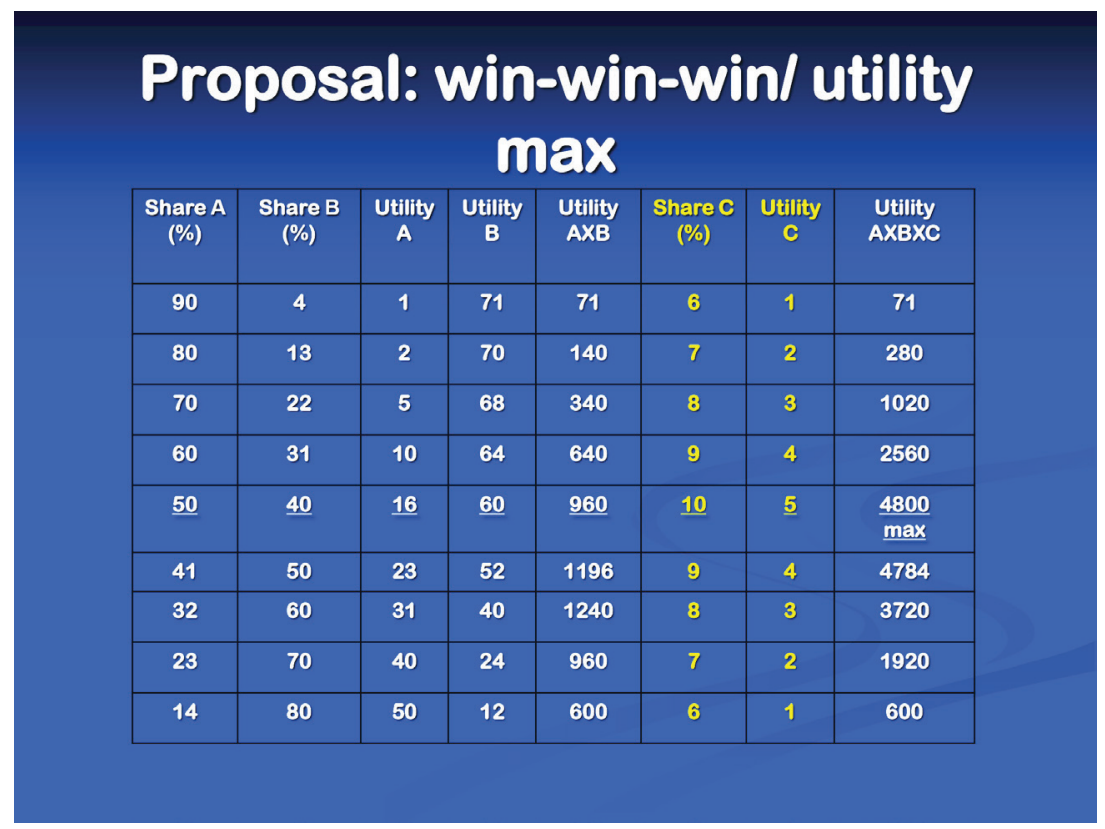

\section{CONCLUSION}

Elephants, in Sri-Lanka are not only a tourist attractive pole, but even more a factor of Nature-human EQUILIBRIUM. Elephants by their activities may influence our behavior for them may influence the way of thinking, our food priorities, through the dynamical, non-linear systems. Relations between human and elephants will continue to be a conflict; if human have not a reference point, except their own selfish. Instead of, human must create in their mind the "natural environmental sensitization" as a third (3rd) fantastic part in a "bargain between 2 " (human and elephants). North western WAR consists of unique conservation problem with regard to free range elephants. Unlike all other WARs of Sri Lanka, this region has the lowest coverage of Wildlife protected areas. Except Wilpattu National Park, the total extent of all the other wildlife protected areas in this region sizes less than 31,000ha.

5. In this term, scientists (rontos and alle) have not right, as they try to solve it, by probabilities bargaining problem is a mainly a sharing problem 
$U_{A}, U_{B}, U_{C}$

when

$U_{A}=x$

$U_{B}=y$

$U_{c}=(100-x-y)$

$U_{A} \cap U_{B} \cap U_{C}=U_{A} \times U_{B} \times U_{C}=M A X \Leftrightarrow\left(U_{A} \times U_{B} \times U_{C}\right)^{\prime}=0$

$x(100-x)^{n}=M A X \Leftrightarrow\left[x(100-x-y)^{n}\right]^{\prime}=0$

generally,

$(f(x) * g(x))^{\prime}=f^{\prime}(x) * g(x)+f(x) * g^{\prime \prime}(x)$

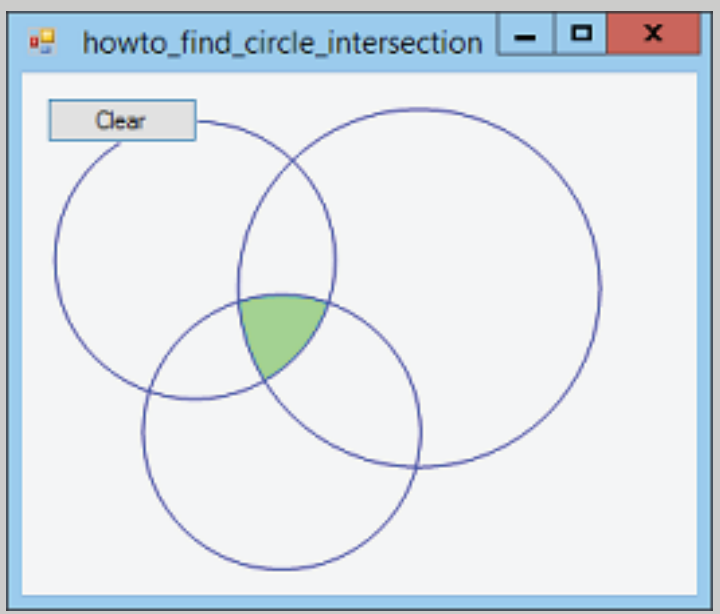

But, 


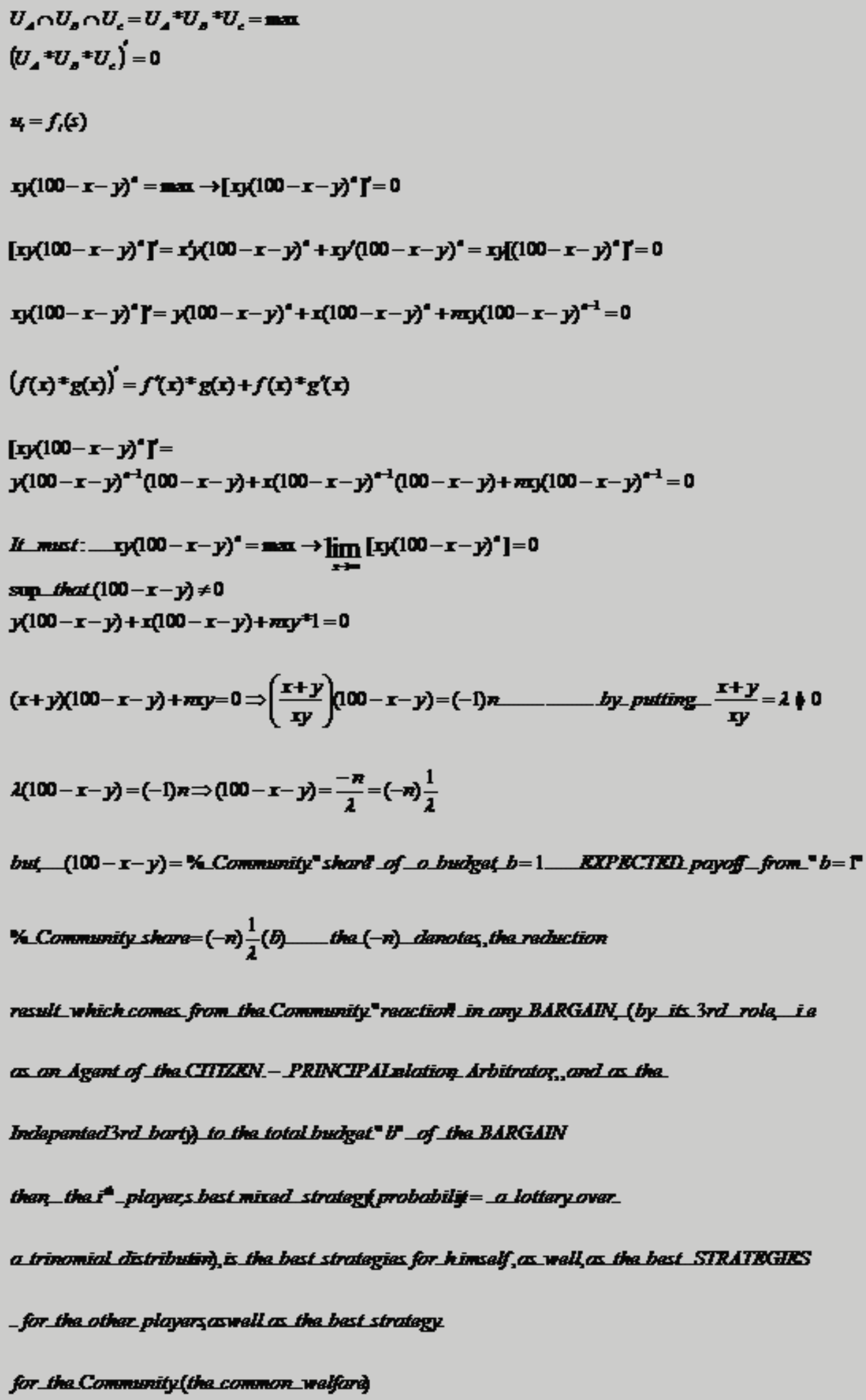


notes:

A,B.C...do,,, not...cooperate.forward

A,B,C..must..collaborate..in..and..during..the..b arg ain..(ins $\tan t . . r e f l e c t i o n . . w i n n i n g . . s t r a t e g i e s)$

$" C "$ "...expresses...not...only ..the..rest..(no..b arg ain..participants $),$,but ...also..the.total..community ..the..word cultural...heritage,world...cultivation...the.." human...being"..."Homo...Sapiens"

From...this..po int..of ...view,...Community ...participation..in..any..b $\arg$ ain...between..TWO(2)..is..necessary

Also,..COMMUNITY -the.."c"..factor..MUST ...express..the.."Community ..Fear"..from..the...b arg ain,..between..A , B

For..this.."Community..participation"..is..captured..as...(100-x-y $)^{n}$, where..n $=$ the..fear..factor..(nonlinear $)$,while.

the..A, B..utility ..functions...must..be..linear

$\lambda=1, . x * \% \ldots \frac{n}{1} \%=100 \%=\max (q u i t e . . u n e q u a l i t y .$. and..unjustice..in..distibution...of .A, B, and..Community)

$\lambda=2 \ldots x * 0=\frac{n}{2} \%=50-50-0$

$\lambda=3 \ldots x * \%=\frac{n}{3} \% . .=33,3333 \ldots I D E A L \ldots S I T U A T I O N$

$\lambda=4+\ldots . . . x * \%=. \frac{x}{4+} \%=U N S T A B L E .(T H E O C H A R I S-O S C I L L A T I O N) \ldots o f . . A, B, C .$. expectations 
Let

H_as_the spper_-_right_bowowloy_of_P

Obviously, $H \subset P_{z}$, is the efficient frontier of $P$

Let $t=\left(t_{1}, t_{2}\right) \in P$ be the vector_of disagneement_payoffs of -person 1

and

person 2, nespectivaly, $t_{i}(i=1,2,-) \in P$ being the payoff that person $i$

gets, if the porties_foil to agnee

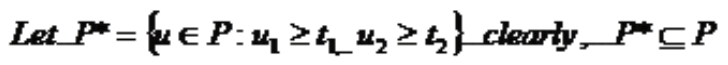

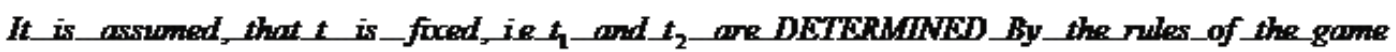

Let $H^{*}$ denote the ypper - ghrite boudony_of $-P^{*}$ Thes, $H^{*} \subseteq P$

The BARGAINIF, PROBLEM is, then:

- Given $P$ - ond $t$, whot will be the solution $\bar{\mu}=\left(\bar{u}_{1}, \bar{u}_{2}\right)$, that the barg aining

_parties_will_eventwally_neach, ASSUMNG_all_individuals_act_rationaly?

e

Is the point satisfying, the

$$
\left(\bar{u}_{1}-t_{1}\right)\left(\bar{u}_{2}-t_{2}\right)=\max _{u \in P}\left[\left(u_{1}-t_{1}\right)\left(u_{2}-t_{2}\right)\right]
$$

such that,

$$
u_{i} \geq t_{i, \ldots} i=1,2
$$


Elephant drives may also cause increase in HEC by making elephants more aggressive. Most bull elephants, who are the main crop raiders, either return to where they have been driven from, or avoid being driven. The Government of Sri Lankamust take measures to ensure the survival of elephants, the country's "treasure" Although the elephanthuman relationship seems to be competitive, conflicting, only the human race can reason, take measures to protect them, enact policies to impose policies to protect the natural environment. In any case, the proposed solution, in the context of "the win-win-win Papakonstantinidis model", has its significance only if it can sensitize the population, local and tourists in this direction. In a re-active perspective, human kind has the first role: In fact the re-active perspective has a low importance, as people have to decide. From the other hand, according to Lorenz'(1972) «butterfly effect» as the, micro-systems' balance may be influenced such as to cause huge spiral destroys. 


\section{RFFERENCES}

Department of Wildlife Conservation. (2013). The first island wide national survey of elephant in Sri Lanka 2011, Department of Wildlife Conservation, Battaramulla, Sri Lanka, 78p.

Department of Wildlife Conservation. (2015). Performance Reports. http://www.dwc.gov.lk/ index.php/en/performance-reports, Retrieved on $3^{\text {rd }}$ March 2016.

Fernando, P. (2006). Elephant conservation in Sri Lanka: Integrating scientific information to guide policy. In: Principles of Conservation Biology, Third Edition, pp. 649-652, Sinauer Associates, Inc. Publishers, Massachusetts, USA.

Fernando, P., M. Kumar, A.C. Williams, E. Wikramanayake, T. Aziz, and S.M. Singh. (2008). Review of Human-Elephant Conflict Mitigation Methods Practiced in South Asia.

Fernando, P. and J. Pastorini. (2011). Range-wide Status of Asian Elephants, Gajah 35: 15-20.

Fernando, P., J. Jayawardene, T. Prasad, W. Hendavitharana, and J. Pastorini. (2011). Current Status of Asian elephants in Sri Lanka, Gajah 35: 93-103.

Choudhury, A., D.K. Lahiri Choudhury, A. Desai, J.W. Duckworth, P.S. Easa, A.J.T. Johnsingh, P. Fernando, S. Hedges, M. Gunawardena, F. Kurt, U. Karanth, A. Lister, V. Menon, H. Riddle, A. Rübel, and E. Wikramanayake. (2008). Elephas maximus. The IUCN Red List of Threatened Species. http://dx.doi.org/10.2305/IUCN.UK.2008.RLTS.Tr140A12828813. en.

Leimgruber, P., J.B. Gagnon, C. Wemmer, D.S. Kelly, M.A. Songer, and E.R. Selig. (2003). Fragmentation of Asia's remaining wildlands: implications for Asian elephant conservation, Animal Conservation 6: 347-359.

Nash, J.F. (1950). Equilibrium points in n-person games. Proceedings of the National Academy of Sciences 36: 48-49.

Papakonstantinidis, L.A. (2003). Sensitization as a form of knowledge creation and the WinWin-Win Model. Scientific Review of Applied Research 8(2): 89-108.

Papakonstantinidis, L.A. (2004a). Operations Management by a hyper-cube \&e win-winwin perspective: A Local Development Approach. Journal of Applied Economics and Management 2(2): 111-130.

Papakonstantinidis, L.A. (2004b). Knowledge Creation and the win-win-win model. Scientific Review of Applied Economics.

Papakonstantinidis, L. (2007). New approaches to rural regional development and rural tourism SMEs. Editorial Policy 1(1): 160.

Papakonstantinidis, L.A. (2010). Applying the Win-Win-Win Papakonstantinidis Model in School Management Crisis-The Greek Case. In: XVII ISA World Congress of Sociology 17: 35\%.

Papakonstantinidis, L.A. (2016). Volume II titled "The "win-win-win Papakonstantinidis model" VOLUME II: COLLECTION social choice, social welfare: theoretical background 2016 . RESEARCH GATE

Prakash, S.L. (2014). Life with Elephants (in Sinhala), Center for Conservation and Research, Rajagiriya, Sri Lanka, 240p.

World Wide Fund for Nature. (2017). Asian elephants. https://www.worldwildlife.org/species/ asian-elephant, Retrieved on $26^{\text {th }}$ December2016. 